\title{
MEMS-Based Endoscopic Optical Coherence Tomography
}

\author{
Jingjing Sun and Huikai Xie \\ Department of Electrical and Computer Engineering, University of Florida, Gainesville, FL 32611, USA \\ Correspondence should be addressed to Jingjing Sun, sunjingjingmia@ufl.edu
}

Received 31 January 2011; Accepted 1 April 2011

Academic Editor: Jianan Qu

Copyright $\odot 2011$ J. Sun and H. Xie. This is an open access article distributed under the Creative Commons Attribution License, which permits unrestricted use, distribution, and reproduction in any medium, provided the original work is properly cited.

\begin{abstract}
Early cancer detection has been playing an important role in reducing cancer mortality. Optical coherence tomography (OCT), due to its micron-scale resolution, has the ability to detect cancerous tissues at their early stages. For internal organs, endoscopic probes are needed as the penetration depth of OCT is about 1-3 mm. MEMS technology has the advantages of fast speed, small size, and low cost, and it has been widely used as the scanning engine in endoscopic OCT probes. Research results have shown great potential for OCT in endoscopic imaging by incorporating MEMS scanning mirrors. Various MEMS-OCT designs are introduced, and their imaging results are reviewed in the paper.
\end{abstract}

\section{Introduction}

Cancer has been one of the deadliest diseases in America and all around the world, killing over 7 million people each year [1]. To detect cancer at the stage when it is still curable has been found to be the most effective way to reduce its death rate. The traditional method for cancer detection is biopsy. It suffers from several drawbacks, such as long diagnosis time, random sample selection and invasiveness. Several noninvasive imaging methods have been employed for clinical use, including ultrasound, CT and MRI. But the resolutions of these modalities are on the order of $100 \mu \mathrm{m}$, not enough to resolve the precancerous lesions, which are normally 5 to $10 \mu \mathrm{m}$ in size. Other issues involved with these methods are low contrast, high costs, and radiation problems.

Optical coherence tomography (OCT) is a relatively new optical imaging modality [2]. By using the short coherence length of a broadband light source, the resolution of OCT can reach 1 to $15 \mu \mathrm{m}$ depending on the light source employed. The penetration depth of OCT is normally 1 to $3 \mathrm{~mm}$, which is sufficient to image the depth of the epithelial layer, where most cancers are originated. In addition to that, OCT is an optical fiber-based system, and thus it is compact, portable, free of radiation, and affordable. Since its introduction in the early 1990s, it has been employed extensively in dermatology and ophthalmology [2-9]. It has also been used for imaging internal organs such as the GI tracts, bladders, and esophagus [10-19].

Figure 1 shows the schematic representation of a frequency domain OCT system. It employs a Michelson interferometer. The input light from a broadband frequency sweeping light source is divided into the reference arm and sample arm. The light beams on both arms are reflected back and form an interference signal at one port of the beam splitter. This interference signal is picked up by a photodetector and provides the depth information of the sample through inverse Fourier transform. And depth resolution is determined by the bandwidth of the light source. To realize $3 \mathrm{D}$ imaging, 2D lateral scan needs to be realized by a moving stage or a scanning mirror. One of the main challenges of imaging internal organs is to realize fast lateral scans in small endoscopes that must be able to fit into narrow lumens whose diameters typically are only a few millimeters. Several groups have attempted to solve this problem. Rotating a fiber-prism module at the distal end has been used to realize side view imaging [20]. Fiber bundle [21], rotating paired GRIN lenses [15], or swinging a fiber tip can be used for front view imaging $[16-19,22]$. Galvanometric actuation [17], electroactive polymers [18], and piezoelectric cantilevers $[19,22]$ have all been used to swing fiber tips. When used at its resonance, a piezoelectric cantilever can scan fast enough to realize real time imaging [19]. However, several drawbacks are associated with these approaches. First, 


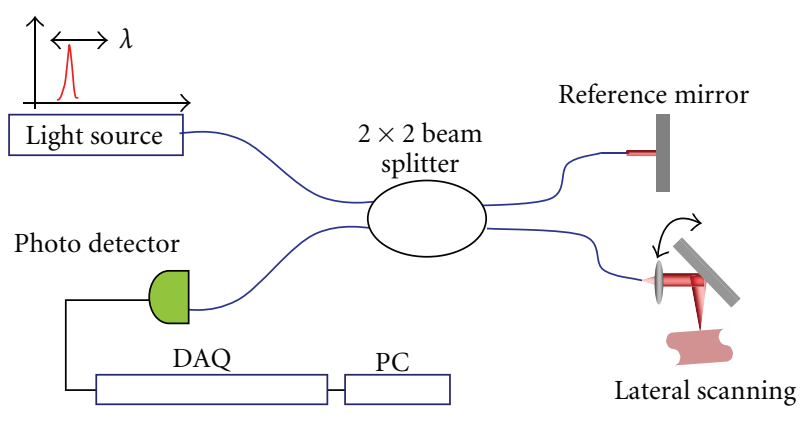

FIgURE 1: OCT system schematic.

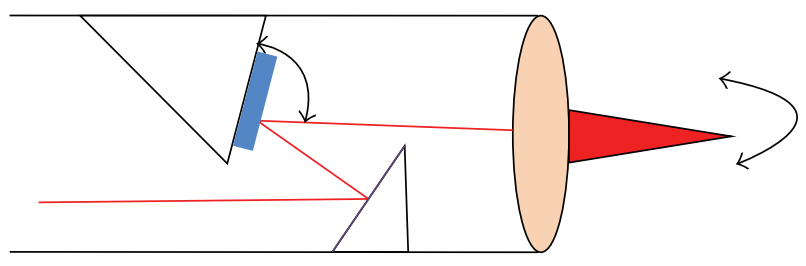

(a)

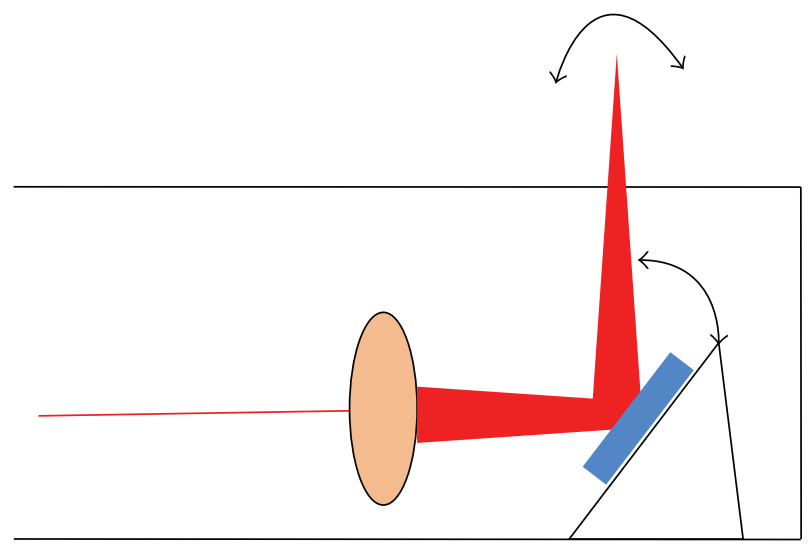

(b)

FIGURE 2: MEMS probe schematic representation. (a) forward-view probe, (b) side-view probe.

manipulating light beam at the distal fiber end limits the scan speed; second, for rotating optical components, the gears employed hinder further miniaturization of the probes; third, piezoelectric cantilevers have hysteresis problem, and when used at resonance, scan uniformity and coupling efficiency cannot be guaranteed, especially at large scan angles. As a result, an alternative technique, which is based on microelectromechanical systems (MEMS) technology, becomes popular.

\section{MEMS-Based OCT Endoscopic Imaging}

MEMS technology is an enabling technology that makes devices and systems at the scale of micrometers to millimeters [23, 24]. MEMS sensors and actuators have been widely used in automotives for airbag deployment and in other consumer products, such as cell phones, projectors and video game controllers. Recently, MEMS technology has shown great potential in biomedical engineering especially for endoscopic imaging. There are several reasons. First, MEMS devices are small; therefore, miniaturization of the probes are possible. Second, MEMS scanners can operate at high speed for real-time imaging. Third, MEMS scanners are easy to integrate with the rest of the imaging system. Fourth, the cost of MEMS devices is low due to the mass production capability. Fifth, the power consumption is low for MEMS devices. The first MEMS-based OCT endoscope was introduced by Pan et al. employing a one-dimensional (1D) electrothermally actuated MEMS mirror [25]. Twodimensional (2D) porcine bladder cross-sectional imaging was demonstrated. After that various forms of MEMS mirrors have been developed as the scanning engine in endoscopic probes for OCT systems.

Figure 2 illustrates the concept of MEMS-based frontview and side-view OCT probes, in which MEMS mirrors are placed at the distal ends of the probes, and their angular rotation directs the light and generates lateral scans on the sample. Combined with the OCT depth scan provided by the reference mirror scanning, $3 \mathrm{D}$ images can be obtained with 2D MEMS mirrors. Several features are highly desirable of MEMS mirrors for this application. Firstly, the footprint of the MEMS device must be small to fit into small endoscopes; secondly, the mirror aperture must be large and flat for easy optical alignment and high optical resolution; thirdly, the mirror must be able to scan large angles to realize large imaging area; fourthly, the driving voltage must be low to ensure safe use inside human body; finally, the linear control of the scan should be easily implemented to simplify signal processing and image interpretation. Single-crystalsilicon (SCS) or silicon-on-insulator (SOI) substrate can provide large flat and robust device microstructures, and thereby are predominantly used for making MEMS mirrors for endoscopic applications. There are four actuation mechanisms employed for generating the scanning for MEMS mirrors: electrostatic, electromagnetic, piezoelectric, and electrothermal. The following sections review OCT systems using MEMS mirrors driven by each of these mechanisms.

\section{Various MEMS OCT}

3.1. Electrostatic MEMS Mirrors. Electrostatic actuation has been one of the most popular choices for MEMS mirrors. Electrostatic actuation is based on electrostatic force which exists between electrically charged particles. The first MEMS mirror based on this principle was demonstrated by Petersen in 1980 [26]. By employing a parallel-plate structure, the maximum rational angle of the micromirror reached $\pm 2^{\circ}$ at resonance and $300 \mathrm{~V}$ driving voltage. This parallel-plate structure has been adopted by many other researchers and rotation angles as large as $\pm 8^{\circ}$ have been achieved with lower driving voltages in the range of $40 \mathrm{~V}$ to $200 \mathrm{~V}$, but the reported mirror aperture diameters are normally smaller than $500 \mu \mathrm{m}$ [27-34]. What limits this structure from realizing larger scan angle is the pull-in effect. To overcome this problem, vertical comb drive actuation structures were employed [35-40]. The vertical or angular displacement of 


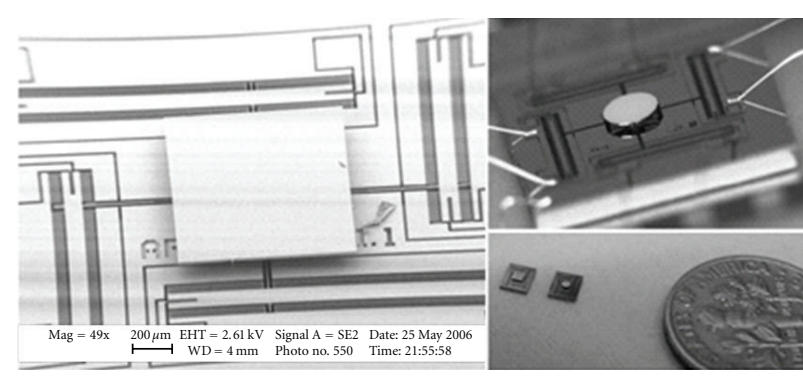

(a) (C) 2007 IEEE

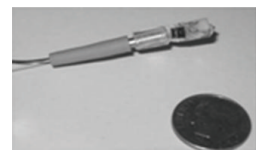

(A)

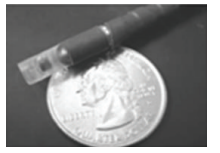

(B)

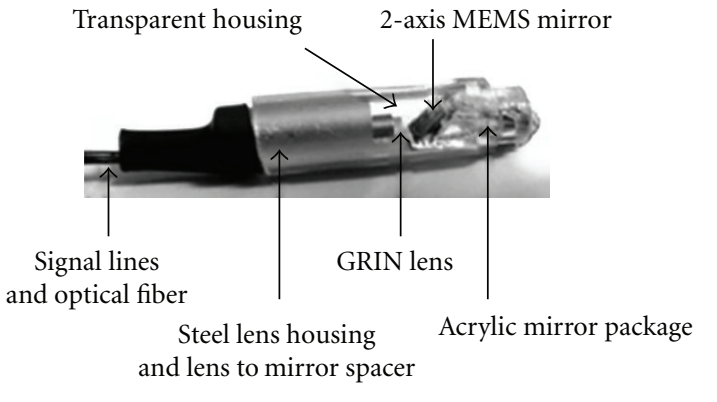

(C)

(c) (C) 2007 IEEE

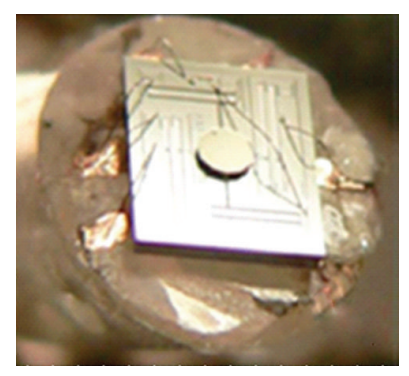

(b) Reprinted with permission from (W. Jung, et al; "Threedimensional endoscopic optical coherence tomography by use of a two-axis microelectromechanical scanning mirror," Applied Physics Letters, vol. 88-163901, pp. 1-3, 2006). Copyright (2006), American Institute of Physics

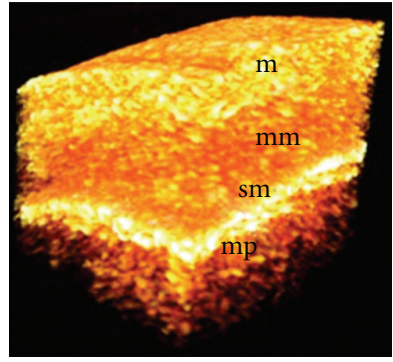

(d) (c) 2007 IEEE

FIGURE 3: Electrostatic MEMS OCT from UC-Irvine/UC-Berkeley. (a) SEMs of two MEMS mirrors, (b) Electrical connection through wire bonding, (c) packaged MEMS probe, (d) 3D image of rabbit rectal tissue.

the comb drives is converted into mirror tilting through a torsional beam which supports the mirror plate. Mirror aperture size as large as $1.5 \mathrm{~mm} \times 1.5 \mathrm{~mm}$ has been reported based on this structure [36]. Both 1D and 2D micromirrors have been realized using this structure, and the mechanical deflection angle has reached $\pm 5.5^{\circ}$ at only $16 \mathrm{~V}$ resonance [36] and $\pm 6.2^{\circ}$ at $55 \mathrm{~V}$ resonance [37]. For 2D mirrors, two gimbals are used to support the mirror plate in orthogonal directions. To further increase scan angles, Milanović et al. proposed a new gimbal-less SOI-based micromirror [38], the static optical deflection for both axes are increased to $\sim \pm 10^{\circ}$ with $\sim 150 \mathrm{~V}$ driving voltage.

A series of endoscopic OCT probes employing electrostatic micromirrors have been reported by Jung and McCormick [41, 42]. Figure 3(a) shows the SEMs of two of the MEMS mirrors they reported. The one on the left has a $1 \mathrm{~mm} \times 1 \mathrm{~mm}$ mirror size on a $2.8 \mathrm{~mm} \times 3.3 \mathrm{~mm}$ footprint, while the one on the right has a mirror aperture diameter of
$800 \mu \mathrm{m}$. The devices employed 2D gimbal-less vertical comb structures. The mirror plate and actuators are fabricated separately and then bonded together. Optical scanning angles of the mirrors can reach $20^{\circ}$ at resonance when a $100 \mathrm{~V}$ driving voltage is applied. Resonant frequencies as high as $2.4 \mathrm{kHz}$ and $1.9 \mathrm{kHz}$ on two axes have been reported. Electrical connection was done through wire bonding, and injection mold was used for probe body. The diameters of the endoscopic probes range from $3.9 \mathrm{~mm}$ to $5.0 \mathrm{~mm}$. 3D in vivo OCT images of healthy rabbit rectal tissue have been obtained at 8 frames/sec. The image volume size is $1 \mathrm{~mm} \times$ $1 \mathrm{~mm} \times 1.4 \mathrm{~mm}$, and the resolution of the image is $20 \mu \mathrm{m}$ $\times 20 \mu \mathrm{m} \times 10 \mu \mathrm{m}$. Important tissue structures can be clearly seen here.

Aguirre et al. from MIT have also reported an electrostatic MEMS mirror-based endoscopic OCT probe [43]. In their paper, they demonstrated a gimbaled 2D MEMS mirror design based on angular vertical comb actuators, which 


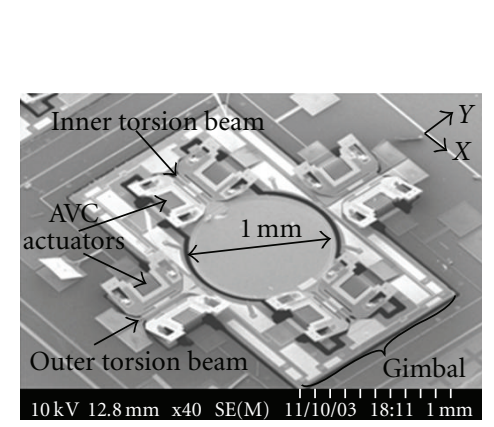

(a)

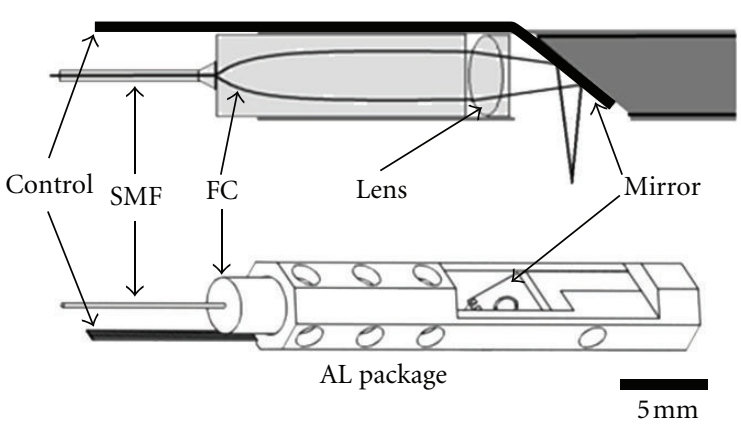

(b)

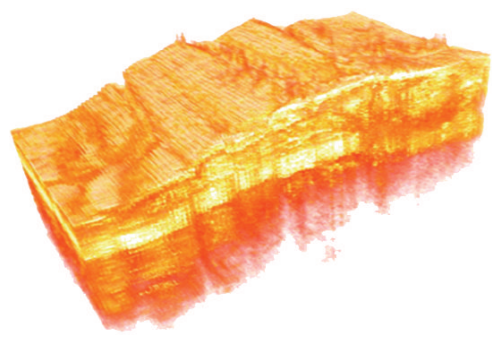

(c)

FIgURE 4: Electrostatic MEMS OCT from MIT. (a) SEMs of the MEMS mirror with angled vertical comb (AVC) actuators. (b) design and packaging of the probe. SMF, single mode fiber. FC, fiber collimator. AL, aluminum. (c) 3D image of hamster cheek pouch. Reprint permission granted by OSA.

allows larger scan angles compared to other vertical comb drives with the same dimensions. The mirror has a circular aperture, whose diameter is $1 \mathrm{~mm}$ and the device footprint is $3 \times 3 \mathrm{~mm}^{2}$, as shown in Figure 4(a). Mechanical scan angles of $\pm 6^{\circ}$ have been achieved on both axes at more than $100 \mathrm{~V}$. The reported a side-view probe with an aluminum holder housing the MEMS mirror. The probe has a diameter of about $5 \mathrm{~mm}$. The optical components packaged inside the probe include a fiber, a GRIN lens and a small achromatic lens (Figure 4(b)). Incorporated in a spectral domain OCT, the probe scans at 4 frames/sec over the range of $1.8 \mathrm{~mm} \times$ $1.0 \mathrm{~mm} \times 1.3 \mathrm{~mm}$. 3D hamster cheek pouch images have been obtained to demonstrate the capability of the probe.

As is shown in Figure 3(b), the probe size is limited by the footprint of the MEMS mirror. For electrostatic mirrors, much space of the device is taken by the comb drive actuators. This results in a small ratio of the mirror aperture size to the device footprint size, or small fill-factor for electrostatic mirrors, which may limit further miniaturization of endoscopic probes. High resonant frequencies make them ideal for fast scanning applications, but working at resonance can cause nonlinear scan. High driving voltage required may also be a concern for endoscopic applications.

3.2. Electromagnetic MEMS Mirrors. To further increase the scanning range and lower the driving voltage, electromagnetic mirrors are also explored for endoscopic OCT applications. Electromagnetic actuation is based on Lorentz force, and larger driving force can be realized with lower driving voltage. By controlling the current flowing direction, both repulsive and attractive driving force can be realized
[44]. The magnetic field for electromagnetic actuation is normally generated by permalloy [44-46] or active electric coils $[44,47,48]$. A $1 \mathrm{D}$ micromirror with over $60^{\circ}$ deflection angles has been reported by Miller and Tai [44]. A 2D micromirror with a mirror plate as large as $3.5 \mathrm{~mm} \times 3.5 \mathrm{~mm}$ has been demonstrated, and, with a $20 \mathrm{~mA}$ driving current at its $2 \mathrm{kHz}$ resonance, the mirror scan angle can reach $\pm 1.51^{\circ}$, and the movable frame can scan $\pm 5.71^{\circ}$ [49]. Yang et al. proposed a coilless design, in which the optical scan angle can reach $20^{\circ}$ with a $2 \mathrm{~mm} \times 2 \mathrm{~mm}$ mirror plate when the mirror is operated at an input power of $9 \mathrm{~mW}$ [50].

Kim et al. demonstrated a 2D electromagnetic MEMS mirror based endoscopic OCT probe [51]. A 2D gimbaled mirror design was employed. A permanent magnet was glued to the backside of the mirror plate, and wire-wound coils were placed inside the probe body for each scan direction. The mirror plate was $0.6 \mathrm{~mm} \times 0.8 \mathrm{~mm}$ and the device footprint was $2.4 \mathrm{~mm} \times 2.9 \mathrm{~mm}$, as shown in Figure 5 . About $\pm 30^{\circ}$ optical scan angle was obtained with $\pm 1.2 \mathrm{~V}$ and $\pm 4 \mathrm{~V}$ driving voltages for the inner and outer axis, corresponding to $50 \mathrm{~mA}$ and $100 \mathrm{~mA}$ current respectively. A probe with a $2.8 \mathrm{~mm}$ diameter and $12 \mathrm{~mm}$ length has been demonstrated with SD-OCT. 3D images of finger tips were obtained at $18.5 \mathrm{frames} / \mathrm{s}$. $\pm 2.8 \mathrm{~V}$ and $\pm 0.8 \mathrm{~V}$ voltages were applied on the inner and outer axis, covering $1.5 \mathrm{~mm} \times 1 \mathrm{~mm}$ lateral scan range and consuming a $150 \mathrm{~mW}$ power in total.

Watanabe et al. have recently demonstrated another electromagnetic MEMS OCT probe [52]. The fabricated mirror module is shown in Figure 6. The mirror plate size is $1.8 \times 1.8 \mathrm{~mm}^{2}$, and the device chip is as large as $10 \times$ $10 \times 0.2 \mathrm{~mm}^{3}$ due to the large electrical coil required. The 


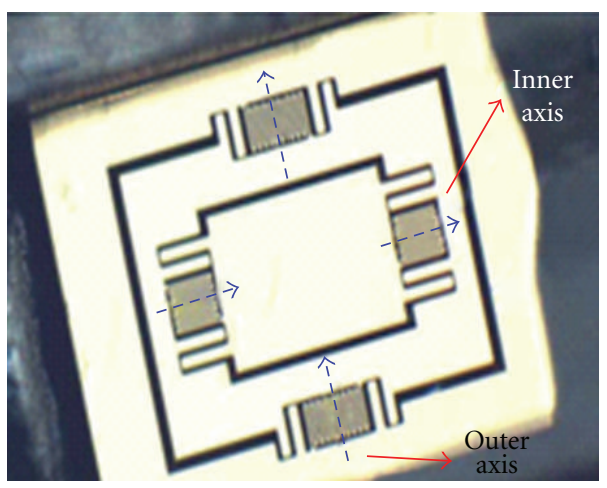

(a)

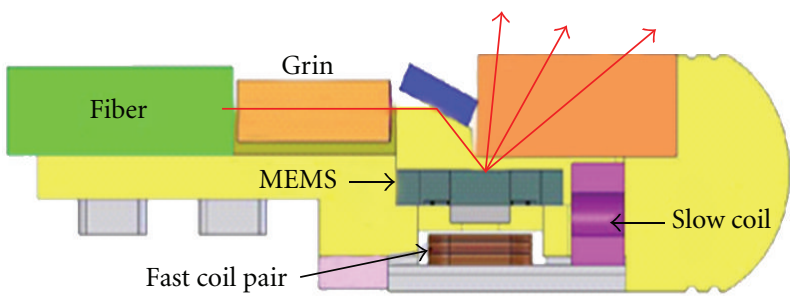

(c)

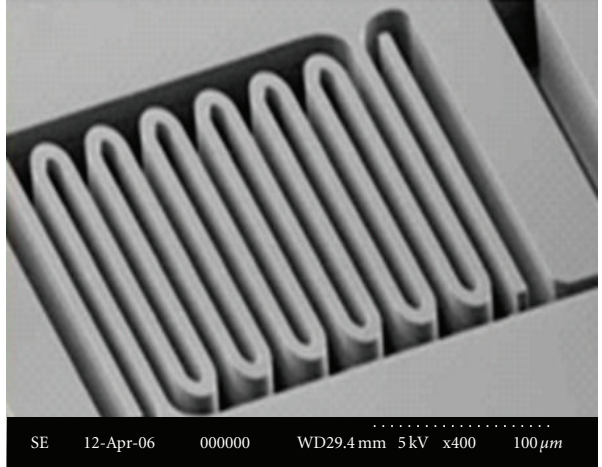

(b)

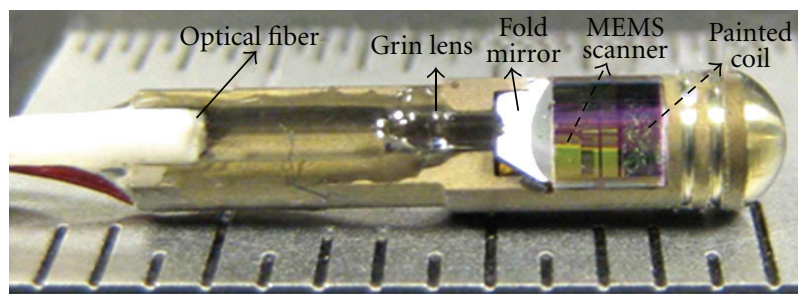

(d)

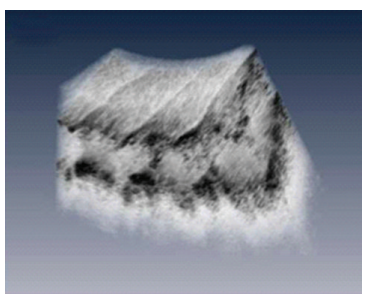

(e)

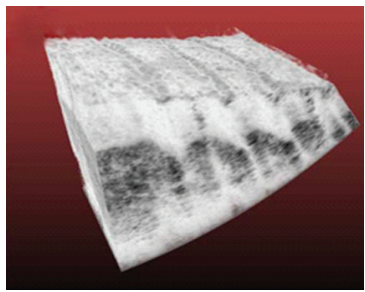

(f)

FIGURE 5: Electromagnetic MEMS OCT reported by Kim et al. (a) (b)SEMs of the MEMS mirror, (c) (d)design and packaging of the probe, (e) (f) 3D image of finger tip. Reprint permission granted by OSA.

entire device was placed on a $15 \mathrm{~mm} \times 15 \mathrm{~mm} \times 1 \mathrm{~mm}$ PCB, which is fixed on the holder with a magnet inside. The MEMS mirror was used in a Fourier domain OCT and 3D human finger images were obtained.

One of the drawbacks of electromagnetic mirrors for endoscopic application is its high power consumption. The other drawbacks lie in the fact that external magnets are required for actuation, which not only greatly complicates the packaging process, but also constraints the further miniaturization of the probes. Electromagnetic interference is also a concern.

\subsection{Piezoelectric MEMS Mirrors. Piezoelectric actuation has} also attracted some attention. It takes advantage of the piezoelectric effect and realizes bending motion by applying electric field across a piezoelectric material such as lead zirconate titanate (PZT). The advantages of piezoelectric actuation include fast response, large bandwidth, and low power consumption. Piezoelectric actuators are usually composed of metal/PZT/metal sandwich [53-56] or double layered PZT materials [57]. Scanning angles as large as $40^{\circ}$ have been reported, using voltages up to $13 \mathrm{~V}$ [58].
A piezoelectric MEMS based OCT probe has also been reported [59]. Piezoelectric MEMS mirrors with aperture sizes of $600 \mu \mathrm{m} \times 840 \mu \mathrm{m}$ and $840 \mu \mathrm{m} \times 1600 \mu \mathrm{m}$ have been fabricated. Mechanical scan angles up to $\pm 7^{\circ}$ and resonant frequency up to $1 \mathrm{kHz}$ were measured for the mirrors. A prove-of-concept probe design is shown in Figure 7(b). The $600 \mu \mathrm{m} \times 840 \mu \mathrm{m}$ mirror was used in an FD-OCT system to demonstrate its imaging capability, and a $2 \mathrm{D}$ image (Figure 7(c)) of an IR card was obtained.

However, the mirrors are only one dimensional and two mirrors scanning at orthogonal directions are required for 3D imaging. Also, the large initial tilt angle will complicate optical alignment and probe packaging. Furthermore, for piezoelectric MEMS mirrors to be used for in vivo OCT imaging applications, charge leakage problems and hysteresis effect still need to be overcome.

3.4. Electrothermal MEMS Mirrors. Electrothermal actuation is studied to further increase the scanning range at low driving voltage. Electrothermal actuation can be realized by using bimorph beams. A bimorph beam is formed by two layers of materials with different thermal expansion coefficients. The 


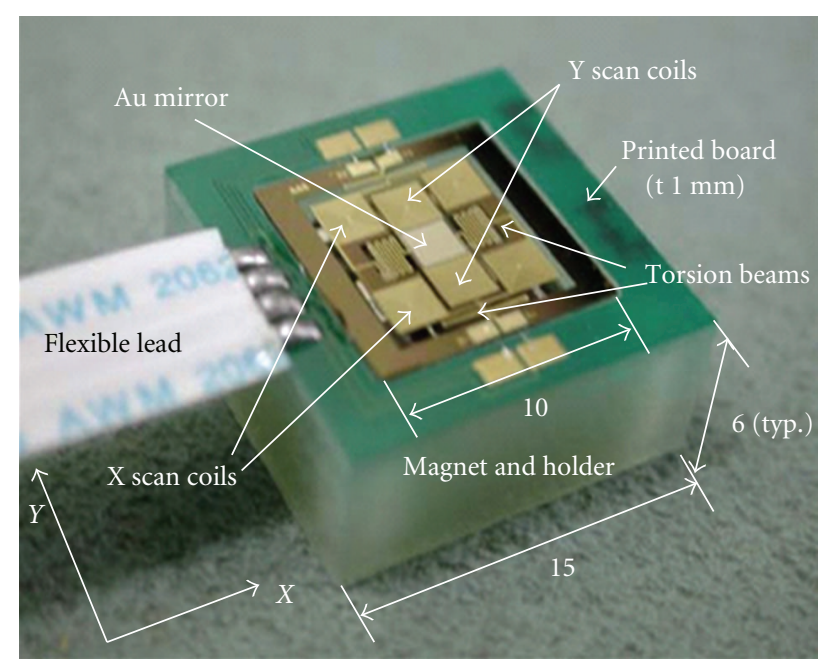

(a)

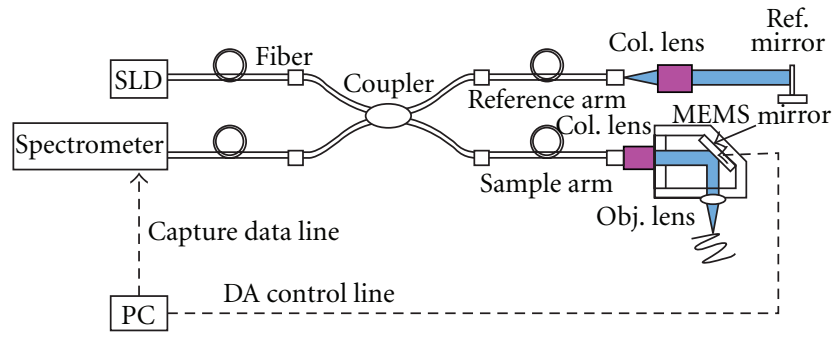

(b)

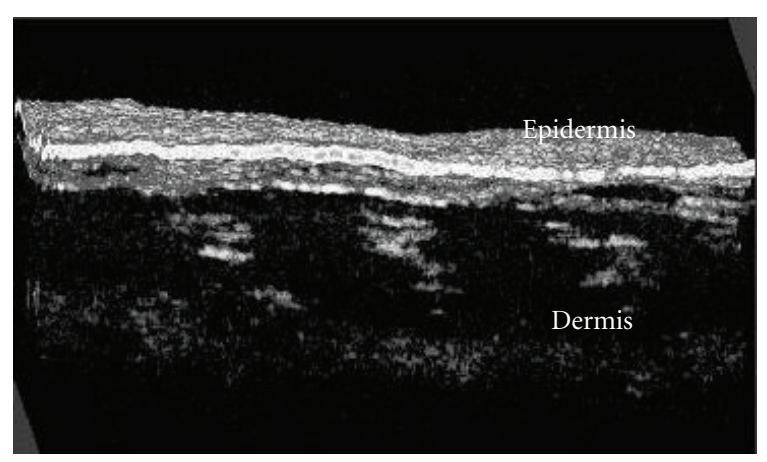

(c)

FIgURE 6: Electromagnetic MEMS OCT from Yamagata Research Institute of Technology, Japan. (a) MEMS mirror module, (b) MEMS probe in OCT system, (c) 3D image of human finger tip. All rights reserved by the Institute of Electrical Engineers of Japan.

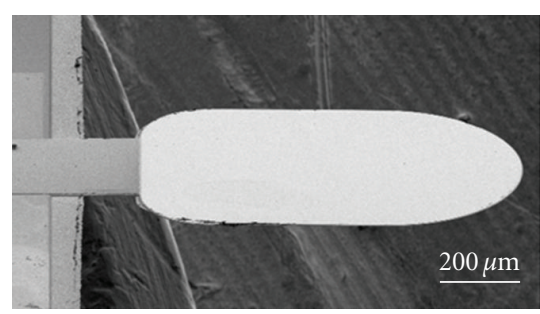

(a)

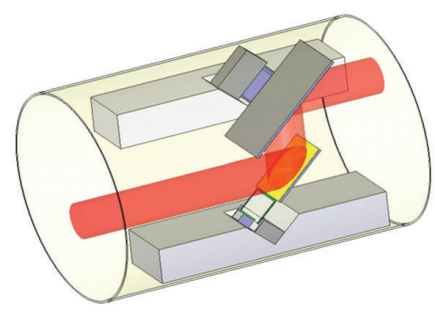

(b)

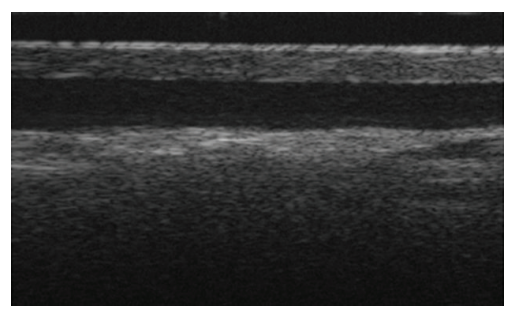

(c)

Figure 7: Piezoelectric MEMS OCT reported by Gilchrist et al. (a) SEM of MEMS mirror, (b) 3D MEMS probe design, (c) 2D image of IR card. Reprint permission granted by IOP.

bending motion of the beam is induced by the expansion difference of the two materials in response to a temperature change. The actuation force typically is larger than that of electrostatic or electromagnetic actuation. Electrothermal micromirrors also have almost linear response between the scan angle and applied voltage, simple structure design, and easy fabrication. One of the most important features of electrothermal mirrors is the high fill factor. For the same mirror aperture size, the device can be smaller, which is crucial for making smaller endoscopic probes. Different materials have been explored for bimorph beams [60-67], including silicon $(\mathrm{Si})$, various metals, such as aluminum (Al), polymers, and dielectrics. The most popular choice is $\mathrm{Al}$ and $\mathrm{SiO}_{2}$. It was first demonstrated by Bühler et al. in 1995 [61]. Then, Jain et al. demonstrated 2D micromirrors based on $\mathrm{Al} / \mathrm{SiO}_{2}$ bimorph beams and polysilicon as the heating material with rotation angle up to $40^{\circ}$ on a $1 \times 1 \mathrm{~mm}^{2}$ mirror plate at $15 \mathrm{~V}$ [68].

Electrothermal actuation was the first of the four actuation mechanisms to be used in endoscopic OCT imaging 


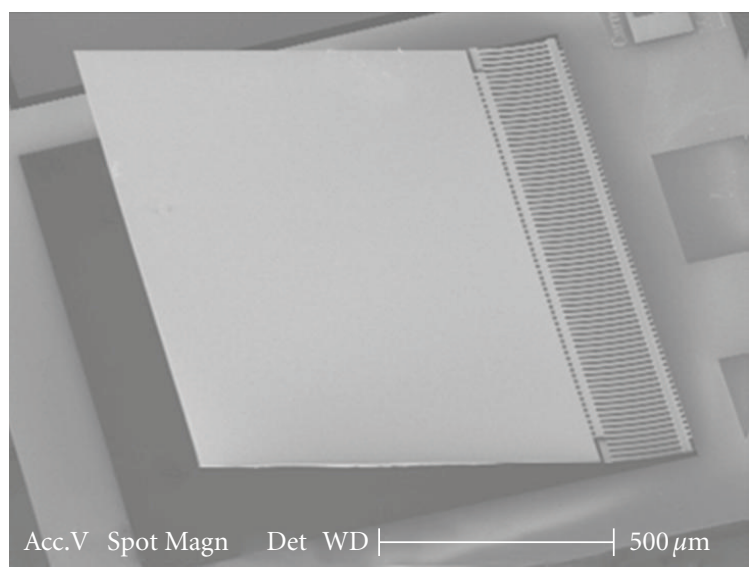

(a) (C) 2003 IEEE

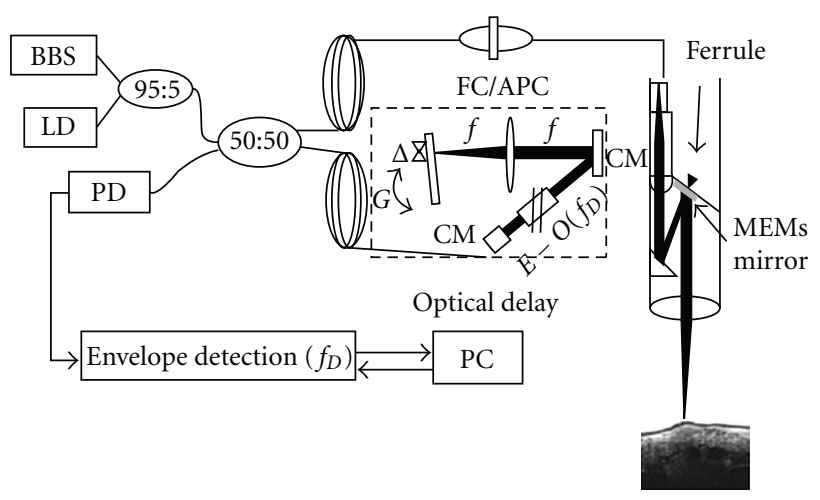

(d) ㄷ 2003 IEEE

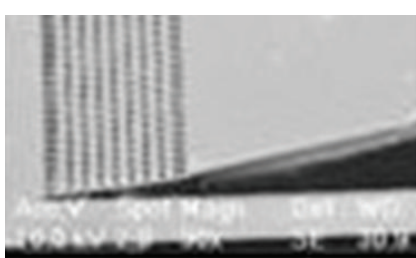

(b) (c) 2003 IEEE

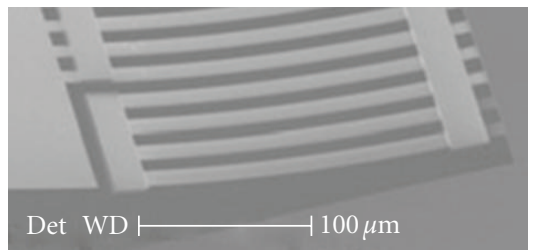

(c) ㄷ 2003 IEEE

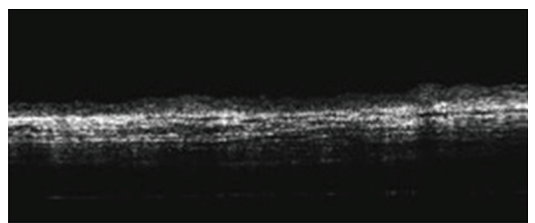

(e) (c) 2003 IEEE

FIGURE 8: Electrothermal MEMS OCT reported by Pan et al. (a) SEM of 1D MEMS mirror, (b) meshed actuator structure, (c) parallel beam structure, (d) OCT system with forward looking endoscopic probe design, and (e) 2D OCT image of rabbit bladder.

$[25,69]$. Xie et al. reported a 1D SCS MEMS mirror. The mirror aperture size was $1 \mathrm{~mm} \times 1 \mathrm{~mm}$, and $17^{\circ}$ rotation angle and $165 \mathrm{~Hz}$ resonance frequency were measured. A forward-looking probe was demonstrated and applied for in vivo imaging of porcine urinary bladders. A 5 frames/s imaging speed was achieved, while the imaging area covered was $2.9 \mathrm{~mm} \times 2.8 \mathrm{~mm}$. Due to the mesh actuator design employed, a $10^{\circ}$ scan discontinuity was observed. Later in 2003, the actuator design was improved by replacing it with a paralleled actuator beam structure, resulting in continuous angular scanning with the scan angle increased to $37^{\circ}[70]$. 2D ex vivo imaging of a rabbit bladder, as shown in Figure 8(e), was obtained to demonstrate the probe capability.

More recently, Xu et al. also reported an electrothermal actuation-based MEMS OCT probe [71-74]. They have demonstrated a series of MEMS mirrors with both straight and curled shaped electrothermal bimorph actuators formed by Aluminum and Silicon. The largest mechanical deflection reported was $17^{\circ}$ at an operation voltage of $\sim 1.3 \mathrm{~V}[71]$. The device has a $500 \mu \mathrm{m}$ diameter mirror aperture on top of a $1.5 \mathrm{~mm} \times 1.5 \mathrm{~mm}$ chip. The mirror showed good linearity between driving voltage and scan angle after the initial critical voltage, and the $3 \mathrm{~dB}$ cutoff frequency was $46 \mathrm{~Hz}$. The probe assembly was based on silicon optical bench ( $\mathrm{SiOB}$ ) methodology for self-alignment of the optical components, and the electrical connection from the MEMS mirror to the copper wires on the substrate was made through solder balls. The probe was then inserted into a transparent housing. The diameter of the probe was less than $4 \mathrm{~mm}$, and the rigid length was about $25 \mathrm{~mm}$. The probe was used in a swept source OCT system at a frame rate of 21.5 frames/sec for 3D imaging, and the imaging results of an IR card were shown in Figure 9(c).

The authors have also reported a series of electrothermal MEMS mirror-based 3D endoscopic OCT probe [75-77]. In these MEMS mirrors, $\mathrm{Al} / \mathrm{SiO}_{2}$ bimorph beams are employed with platinum as the heating material. The actuators are designed in a folded fashion and symmetrically placed on four sides of the mirror plate to reduce the actuator space and realize lateral shift free scan motion. In one design, as shown in Figure 10(a) the mirror plate is $1 \mathrm{~mm} \times 1 \mathrm{~mm}$ and the device footprint is $2 \mathrm{~mm} \times 2 \mathrm{~mm}$, resulting in a $25 \%$ fill factor. The scanning angle of the mirror reaches $\pm 30^{\circ}$ at only $5.5 \mathrm{~V}$. Electrical connection was made through wire bonding. By using rigid or flexible $\mathrm{PCB}$, two probe 


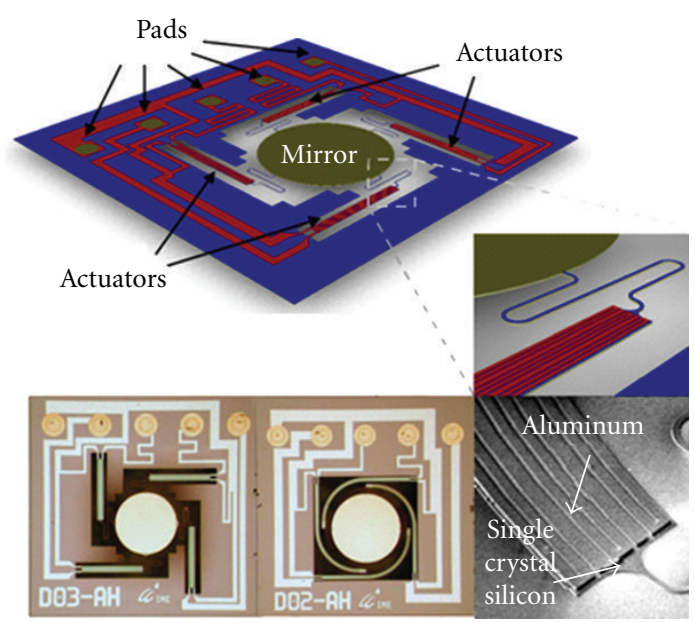

(a)

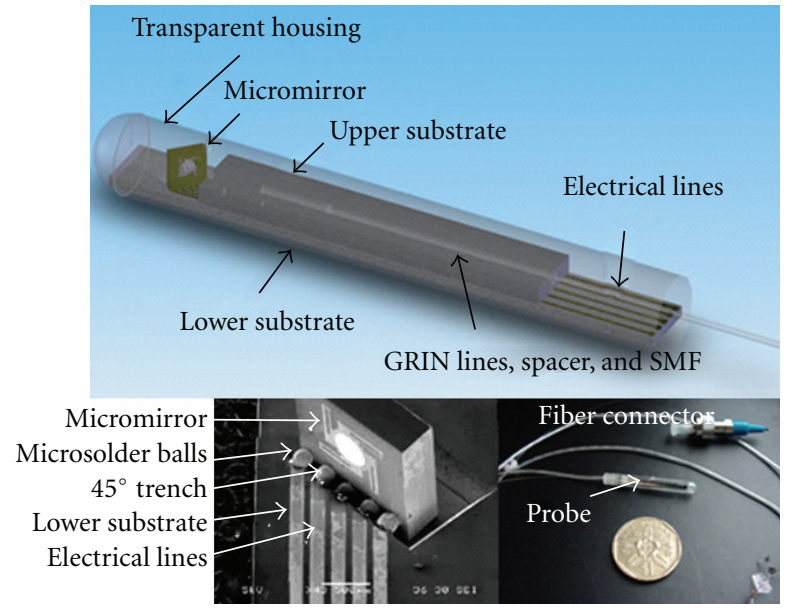

(b)
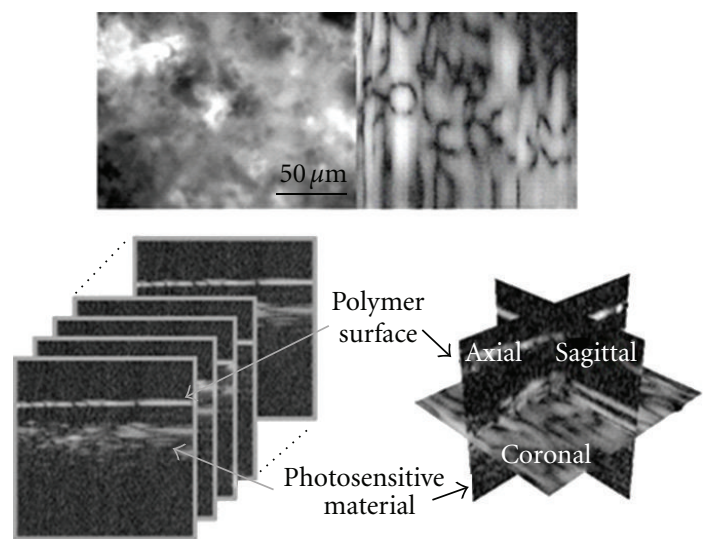

(c)

FIGURE 9: Electrothermal MEMS OCT reported by Xu et al. (a) two-axis electrothermal MEMS mirror, (b) probe design and assembly demonstration, and (c) 2D and 3D OCT image of an IR card. Reprint permission granted by IOP.

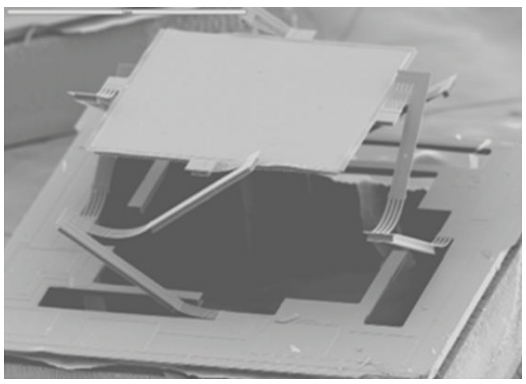

(a) Reprint permission granted by OSA

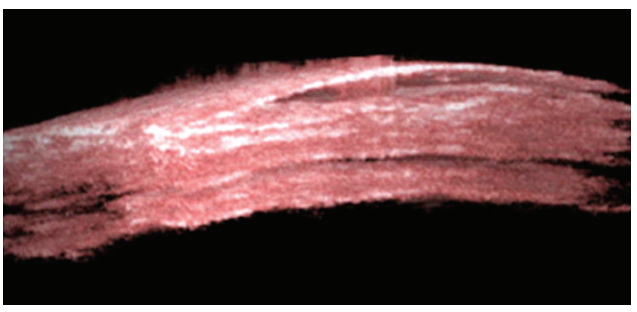

(d) Reprint permission granted by SPIE

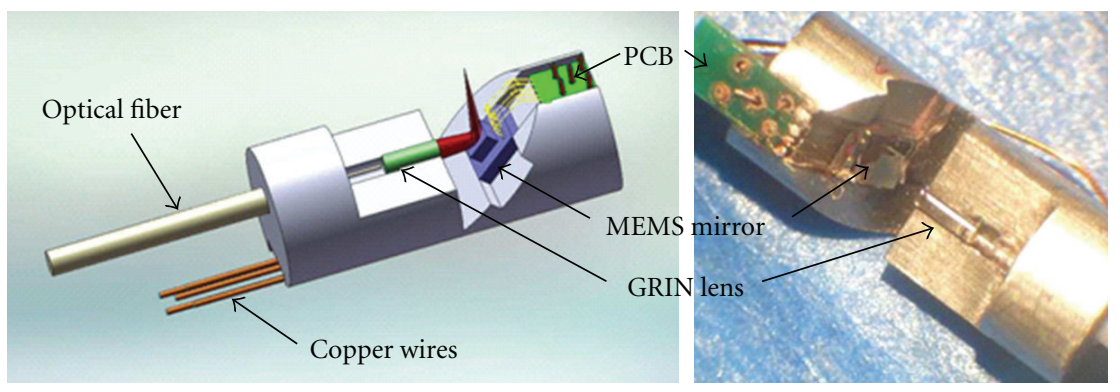

(b) Reprint permission granted by OSA

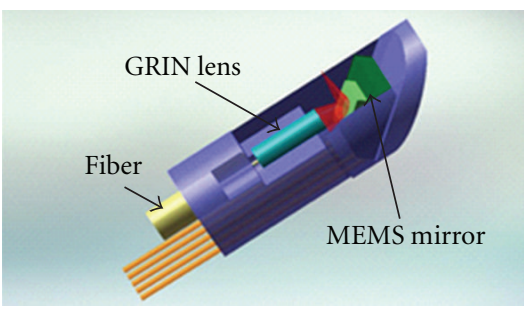

(e) Reprint permission granted by SPIE (c) Reprint permission granted by OSA

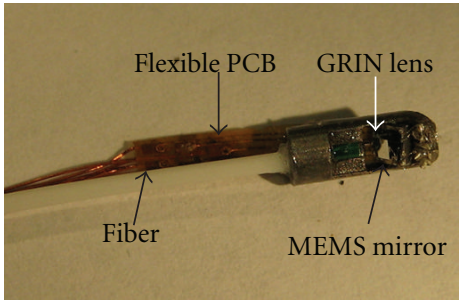

(f) Reprint permission granted by OSA

FIGURE 10: Electrothermal MEMS OCT reported by Sun et al. (a) SEM of electrothermal MEMS mirror, (b) 5 mm probe 3D model, (c) $5 \mathrm{~mm}$ assembled probe, (d) $2.7 \mathrm{~mm}$ probe 3D model, (d) $2.7 \mathrm{~mm}$ assembled probe, (f) 3D OCT image of mouse ear obtained by $5 \mathrm{~mm}$ probe shown in (b) and (c). 


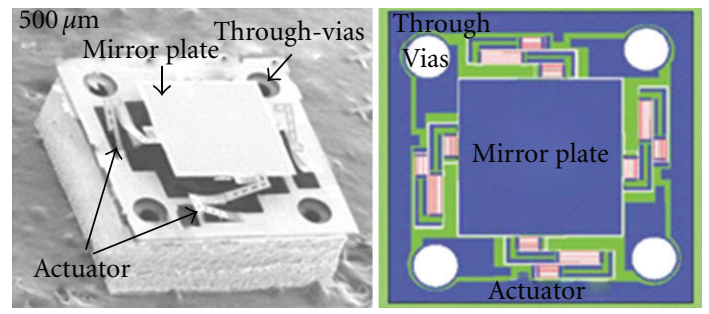

(a)

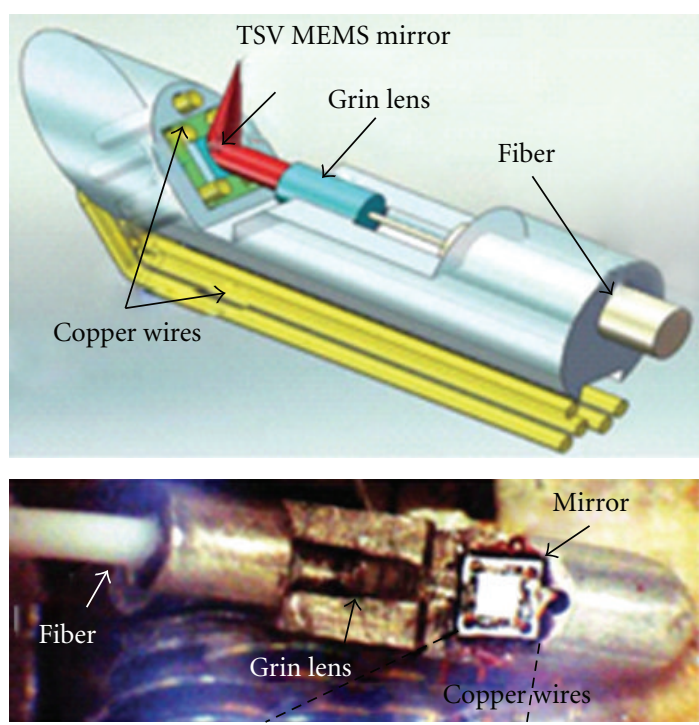

(b)
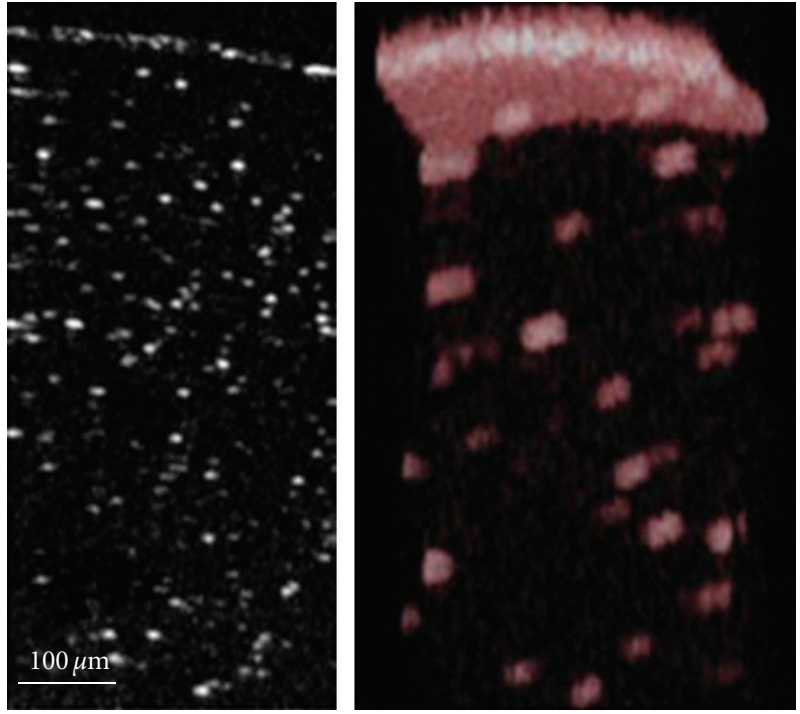

(c)

FIGURE 11: Electrothermal MEMS OCT reported by Liu et al. (a) SEM and schematic of through vias electrothermal MEMS mirror, (b) $2.6 \mathrm{~mm}$ probe 3D model and assembled probe, and (c) 2D and 3D OCT image of microsphere embedded in PDMS. Reprint permission granted by SPIE.

designs with respective outer diameters of $5 \mathrm{~mm}$ (Figures $10(\mathrm{~b})$ and $10(\mathrm{c}))$ and $2.7 \mathrm{~mm}$ (Figures $10(\mathrm{~d})$ and $10(\mathrm{e})$ ) have been demonstrated. 3D imaging was demonstrated with a time-domain OCT system at 2.5 frames/s. The image shown in Figure 10(f) is of a mouse ear obtained using the $5 \mathrm{~mm}$ probe, and the image volume is $2.3 \times 2.3 \times 1.6 \mathrm{~mm}^{3}$.

A newer MEMS mirror design has been developed to improve the probe assembling. As shown in Figure 11(a), the mirror device has through-silicon vias (TSVs) for electrical connections [77]. Four metal pads are located next to the TSVs. As shown in Figure 11(b), copper wires carrying control signals come from the backside of the probe, pass through the TSVs, and then are connected to the pads using silver epoxy. This wire-bonding free design simplifies the assembly process, and enables a larger fill factor. The size of the mirror plate is $0.8 \mathrm{~mm} \times 0.8 \mathrm{~mm}$ and the device footprint is $1.5 \mathrm{~mm} \times 1.5 \mathrm{~mm}$, giving a fill factor of $28.4 \%$. A $16^{\circ}$ optical scan angle was measured at only $3.6 \mathrm{~V}$ DC. The packaged probe size is $2.6 \mathrm{~mm}$. 2D and 3D imaging of microspheres embedded in PDMS was obtained, as shown in Figure 11(c).

\section{Summary}

Of the four actuation mechanisms, electrostatic actuation has fast response and lowest power consumption, but it requires large driving voltage which may not be safe for imaging human internal organs. Electromagnetic actuation 
can realize large scan angle, at low driving voltage, but the permanent magnet required poses difficulties for further probe miniaturization. Piezoelectric MEMS mirrors can also be fast and consume low power, but it must overcome the large initial tilting issues, the hysteresis effect and charge leakage problem for OCT imaging applications. Electrothermal actuation can scan large angles at low driving voltages, and it also has the largest fill factor compared to all three other kinds of MEMS mirrors. Thermal response is relatively slow, but it is capable to realize real-time imaging. Overall, electrothermal MEMS mirrors are the better choice for endoscopic OCT scanners. In the future, for endoscopic imaging applications, the fill factor of MEMS mirrors still need to be increased and better packaging schemes must be designed. Combining MEMS technology with OCT to realize real time in vivo endoscopic 3D imaging has shown great potential. The clinical application of this technology for early cancer detection of internal organs will benefit millions of people worldwide.

\section{References}

[1] American Cancer Society, Cancer Facts and Figures 2010, American Cancer Society, Atlanta, Ga, USA, 2010.

[2] D. Huang, E. A. Swanson, C. P. Lin et al., "Optical coherence tomography," Science, vol. 254, no. 5035, pp. 1178-1181, 1991.

[3] C. A. Puliafito, M. R. Hee, C. P. Lin et al., "Imaging of macular diseases with optical coherence tomography," Ophthalmology, vol. 102, no. 2, pp. 217-229, 1995.

[4] J. S. Schuman, M. R. Hee, A. V. Arya et al., "Optical coherence tomography: a new tool for glaucoma diagnosis," Current Opinion in Ophthalmology, vol. 6, no. 2, pp. 89-95, 1995.

[5] J. G. Fujimoto, "Optical coherence tomography for ultrahigh resolution in vivo imaging," Nature Biotechnology, vol. 21, no. 11, pp. 1361-1367, 2003.

[6] E. A. Swanson, D. Huang, M. R. Hee, J. G. Fujimoto, C. P. Lin, and C. A. Puliafito, "High-speed optical coherence domain reflectometry," Optics Letters, vol. 17, pp. 151-153, 1992.

[7] J. Welzel, "Optical coherence tomography in dermatology: a review," Skin Research and Technology, vol. 7, no. 1, pp. 1-9, 2001.

[8] B. H. Park, C. Saxer, S. M. Srinivas, J. S. Nelson, and J. F. De Boer, "In vivo burn depth determination by high-speed fiberbased polarization sensitive optical coherence tomography," Journal of Biomedical Optics, vol. 6, no. 4, pp. 474-479, 2001.

[9] M. C. Pierce, R. L. Sheridan, B. Hyle Park, B. Cense, and J. F. De Boer, "Collagen denaturation can be quantified in burned human skin using polarization-sensitive optical coherence tomography," Burns, vol. 30, no. 6, pp. 511-517, 2004.

[10] M. V. Sivak, K. Kobayashi, J. A. Izatt et al., "High-resolution endoscopic imaging of the GI tract using optical coherence tomography," Gastrointestinal Endoscopy, vol. 51, no. 4, pp. 474-479, 2000.

[11] S. Jackle, N. Gladkova, F. Feldchtein et al., "In vivo endoscopic optical coherence tomography of esophagitis, Barrett's esophagus, and adenocarcinoma of the esophagus," Endoscopy, vol. 32, no. 10, pp. 750-755, 2000.

[12] X. D. Li, S. A. Boppart, J. Van Dam et al., "Optical coherence tomography: advanced technology for the endoscopic imaging of Barrett's esophagus," Endoscopy, vol. 32, no. 12, pp. 921930, 2000.

[13] J. M. Poneros, S. Brand, B. E. Bouma, G. J. Tearney, C. C. Compton, and N. S. Nishioka, "Diagnosis of specialized intestinal metaplasia by optical coherence tomography," Gastroenterology, vol. 120, no. 1, pp. 7-12, 2001.

[14] G. J. Tearney, M. E. Brezinski, B. E. Bouma et al., "In vivo endoscopic optical biopsy with optical coherence tomography," Science, vol. 276, no. 5321, pp. 2037-2039, 1997.

[15] J. Wu, M. Conry, C. Gu, F. Wang, Z. Yaqoob, and C. Yang, "Paired-angle-rotation scanning optical coherence tomography forward-imaging probe," Optics Letters, vol. 31, no. 9, pp. 1265-1267, 2006.

[16] T. Wu, Z. Ding, K. Wang, M. Chen, and C. Wang, "Twodimensional scanning realized by an asymmetry fiber cantilever driven by single piezo bender actuator for optical coherence tomography," Optics Express, vol. 17, no. 16, pp. 13819-13829, 2009.

[17] A. M. Sergeev, V. M. Gelikonov, G. V. Gelikonov et al., "In vivo endoscopic OCT imaging of precancer and cancer states of human mucosa," Optics Express, vol. 1, no. 13, pp. 432-440, 1997.

[18] Y. Wang, M. Bachman, G. P. Li, S. Guo, B. J. F. Wong, and Z. Chen, "Low-voltage polymer-based scanning cantilever for in vivo optical coherence tomography," Optics Letters, vol. 30, no. 1, pp. 53-55, 2005.

[19] X. Liu, M. J. Cobb, Y. Chen, M. B. Kimmey, and X. Li, "Rapidscanning forward-imaging miniature endoscope for real-time optical coherence tomography," Optics Letters, vol. 29, no. 15, pp. 1763-1765, 2004

[20] H. L. Fu, Y. Leng, M. J. Cobb, K. Hsu, J. H. Hwang, and $\mathrm{X}$. Li, "Flexible miniature compound lens design for highresolution optical coherence tomography balloon imaging catheter," Journal of Biomedical Optics, vol. 13, no. 6, Article ID 060502, 2008.

[21] T. Xie, D. Mukai, S. Guo, M. Brenner, and Z. Chen, "Fiberoptic-bundle-based optical coherence tomography," Optics Letters, vol. 30, no. 14, pp. 1803-1805, 2005.

[22] S. A. Boppart, B. E. Bouma, C. Pitris, G. J. Tearney, J. G. Fujimoto, and M. E. Brezinski, "Forward-imaging instruments for optical coherence tomography," Optics Letters, vol. 22, no. 21, pp. 1618-1620, 1997.

[23] J. M. Bustjllo, R. T. Howe, and R. S. Muller, "Surface micromachining for microelectromechanical systems," Proceedings of the IEEE, vol. 86, no. 8, pp. 1552-1573, 1998.

[24] G. T. A. Kovacs, N. I. Maluf, and K. E. Petersen, "Bulk micromachining of silicon," Proceedings of the IEEE, vol. 86, no. 8, pp. 1536-1551, 1998.

[25] Y. Pan, H. Xie, and G. K. Fedder, "Endoscopic optical coherence tomography based on a microelectromechanical mirror," Optics Letters, vol. 26, no. 24, pp. 1966-1968, 2001.

[26] K. E. Petersen, "Silicon torsional scanning mirror," IBM Journal of Research and Development, vol. 24, no. 5, pp. 631$637,1980$.

[27] L. Fan and M. C. Wu, "Two-dimensional optical scanner with large angular rotation realized by self-assembled microelevator," in Proceedings of the IEEE/LEOS Summer Topical Meeting, pp. 107-108, July 1998.

[28] G. D. J. Su, H. Toshiyoshi, and M. C. Wu, "Surfacemicromachined 2-D optical scanners with high-performance single-crystalline silicon micromirrors," IEEE Photonics Technology Letters, vol. 13, no. 6, pp. 606-608, 2001.

[29] D. S. Greywall, C. S. Pai, S. H. Oh et al., "Monolithic fringefield-activated crystalline silicon tilting-mirror devices," Journal of Microelectromechanical Systems, vol. 12, no. 5, pp. 702707, 2003.

[30] D. S. Greywall, P. A. Busch, F. Pardo, D. W. Carr, G. Bogart, and H. T. Soh, "Crystalline silicon tilting mirrors for optical crossconnect switches," Journal of Microelectromechanical Systems, vol. 12, no. 5, pp. 708-712, 2003. 
[31] Z. Hao, B. Wingfield, M. Whitley, J. Brooks, and J. A. Hammer, "A design methodology for a bulk-micromachined two-dimensional electrostatic torsion micromirror," Journal of Microelectromechanical Systems, vol. 12, no. 5, pp. 692-701, 2003.

[32] J. C. Chiou and Y. C. Lin, "A multiple electrostatic electrodes torsion micromirror device with linear stepping angle effect," Journal of Microelectromechanical Systems, vol. 12, no. 6, pp. 913-920, 2003.

[33] M. R. Dokmeci, A. Pareek, S. Bakshi et al., "Two-axis singlecrystal silicon micromirror arrays," Journal of Microelectromechanical Systems, vol. 13, no. 6, pp. 1006-1017, 2004.

[34] K. Joudrey, G. G. Adams, and N. E. McGruer, "Design, modeling, fabrication and testing of a high aspect ratio electrostatic torsional MEMS micromirror," Journal of Micromechanics and Microengineering, vol. 16, no. 10, pp. 2147-2156, 2006.

[35] R. A. Conant, J. T. Nee, K. Y. Lau, and R. S. Muller, "A flat highfrequency scanning micromirror," in Proceedings of the Hilton Head Solid-State Sensor and Actuator Workshop, pp. 6-9, 2000.

[36] H. Schenk, P. Dun, D. Kunze, H. Laher, and H. Kiick, "An electrostatically excited 2D micro-scanning-mirror with an inplane configuration of the driving electrodes," in Proceedings of the 13th IEEE International Conference on Micro Electro Mechanical Systems (MEMS '00), Miyazaki, Japan, January 2000.

[37] W. Piyawattanametha, P. R. Patterson, D. Hah, H. Toshiyoshi, and M. C. Wu, "Surface- and bulk-micromachined twodimensional scanner driven by angular vertical comb actuators," Journal of Microelectromechanical Systems, vol. 14, no. 6, pp. 1329-1338, 2005.

[38] V. Milanović, G. A. Matus, and D. T. McCormick, "Gimbal-less monolithic silicon actuators for tip-tilt-piston micromirror applications," IEEE Journal on Selected Topics in Quantum Electronics, vol. 10, no. 3, pp. 462-471, 2004.

[39] H. Xie, Y. Pan, and G. K. Fedder, "A CMOS-MEMS mirror with curled-hinge comb drives," Journal of Microelectromechanical Systems, vol. 12, no. 4, pp. 450-457, 2003.

[40] P. R. Patterson, D. Hah, H. Nguyen, H. Toshiyoshi, R. M. Chao, and M. C. Wu, "A scanning micromirror with angular comb drive actuation," in Proceedings of the 15th IEEE International Conference on Micro Electro Mechanical Systems (MEMS '02), pp. 544-547, Las Vegas, Nev, USA, January 2002.

[41] W. Jung, D. T. McCormick, J. Zhang, L. Wang, N. C. Tien, and Z. Chen, "Three-dimensional endoscopic optical coherence tomography by use of a two-axis microelectromechanical scanning mirror," Applied Physics Letters, vol. 88, no. 16, Article ID 163901, 3 pages, 2006.

[42] D. T. McCormick, W. Jung, Y. C. Ahn, Z. Chen, and N. C. Tien, "A three dimensional real-time MEMS based optical biopsy system for in-vivo clinical imaging," in Proceedings of the 4th International Conference on Solid-State Sensors, Actuators and Microsystems (TRANSDUCERS '07), pp. 203-208, June 2007.

[43] A. D. Aguirre, P. R. Herz, Y. Chen et al., "Two-axis MEMS scanning catheter for ultrahigh resolution three-dimensional and En Face imaging," Optics Express, vol. 15, no. 5, pp. 24452453, 2007.

[44] R. A. Miller and Y. C. Tai, "Micromachined electromagnetic scanning mirrors," Optical Engineering, vol. 36, no. 5, pp. 1399-1407, 1997.

[45] A. D. Yalcinkaya, H. Urey, and S. Holmstrom, "NiFe plated biaxial magnetostatic MEMS scanner," in Proceedings of the 14th IEEE International Conference on Solid-State Sensors, Actuators and Microsystems (Transducers '07), pp. 1517-1520, Lyon, France, June 2007.
[46] J. W. Judy and R. S. Muller, "Magnetically actuated, addressable microstructures," Journal of Microelectromechanical Systems, vol. 6, no. 3, pp. 249-255, 1997.

[47] I. J. Cho, K. S. Yun, H. K. Lee, J. B. Yoon, and E. Yoon, "A lowvoltage two-axis electromagnetically actuated micromirror with bulk silicon mirror plates and torsion bars," in Proceedings of the 15th IEEE International Conference on Micro Electro Mechanical Systems (MEMS '02), pp. 540-543, Las Vegas, Nev, USA, January 2002.

[48] J. J. Bernstein, W. P. Taylor, J. D. Brazzle et al., "Electromagnetically actuated mirror arrays for use in 3-D optical switching applications," Journal of Microelectromechanical Systems, vol. 13, no. 3, pp. 526-535, 2004.

[49] SI. H. Ahn and Y. K. Kim, "Silicon scanning mirror of two DOF with compensation current routing," Journal of Micromechanics and Microengineering, vol. 14, no. 11, pp. 1455-1461, 2004.

[50] H. A. Yang, T. L. Tang, S. T. Lee, and W. Fang, "A novel coilless scanning mirror using Eddy current Lorentz force and magnetostatic force," Journal of Microelectromechanical Systems, vol. 16, no. 3, pp. 511-520, 2007.

[51] K. H. Kim, B. H. Park, G. N. Maguluri et al., "Two-axis magnetically-driven MEMS scanning catheter for endoscopic high-speed optical coherence tomography," Optics Express, vol. 15, no. 26, pp. 18130-18140, 2007.

[52] Y. Watanabe, Y. Abe, S. Iwamatsu, S. Kobayashi, Y. Takahashi, and T. Sato, "Electromagnetically driven 2-axis optical beam steering MEMS mirror and its dependence of actuation on magnetic field," IEEJ Transactions on Sensors and Micromachines, vol. 130, no. 4, pp. 107-112, 2010.

[53] T. Kawabata, M. Ikeda, H. Goto, M. Matsumoto, and T. Yada, "2-dimensional micro scanner integrated with PZT thin film actuator," in Proceedings of the International Conference on Solid-State Sensors and Actuators (Transducers '97), pp. 339342, Chicago,Ill, USA, June 1997.

[54] H.-J. Nam, Y.-S. Kim, S.-M. Cho, Y. Yee, and J.-U. Bu, "Low voltage PZT actuated tilting micromirror with hinge structure," in Proceedings of the IEEE/LEOS International Conference on Optical MEMS, Lugano, Switzerland, August 2002.

[55] N. Kikuchi, Y. Haga, M. Maeda, W. Makishi, and M. Esashi, "Piezoelectric 2-D micro scanner for minimally invasive therapy fabricated using femtosecond laser ablation," in Proceedings of the 12th International Conference on Solid State Sensors, Actuators and Microsystems (Transducersv '03), Boston, Mass, USA, June 2003.

[56] Y. Yee, J. U. Bu, M. Ha et al., "Fabrication and characterization of a PZT actuated micromirror with two-axis rotational motion for free space optics," in Proceedings of the 14th IEEE International Conference on Micro Electro Mechanical Systems (MEMS '01), Interlaken, Switzerland, January 2001.

[57] J. Tsaur, L. Zhang, R. Maeda, and S. Matsumoto, "2D micro scanner actuated by sol-gel derived double layered PZT," in Proceedings of the 15th IEEE International Conference on Micro Electro Mechanical Systems (MEMS '02), pp. 548-551, Las Vegas, Nev, USA, January 2002.

[58] J. G. Smits, K. Fujimoto, and V. F. Kleptsyn, "Microelectromechanical flexure PZT actuated optical scanner: static and resonance behavior," Journal of Micromechanics and Microengineering, vol. 15, no. 6, pp. 1285-1293, 2005.

[59] K. H. Gilchrist, R. P. McNabb, J. A. Izatt, and S. Grego, "Piezoelectric scanning mirrors for endoscopic optical coherence tomography," Journal of Micromechanics and Microengineering, vol. 19, no. 9, Article ID 095012, 2009. 
[60] R. A. Buser, N. F. de Rooij, H. Tischhauser, A. Dommann, and G. Staufert, "Biaxial scanning mirror activated by bimorph structures for medical applications," Sensors and Actuators A, vol. 31, no. 1-3, pp. 29-34, 1992.

[61] J. Bühler, J. Funk, O. Paul, F. P. Steiner, and H. Baltes, "Thermally actuated CMOS micromirrors," Sensors and Actuators A, vol. 47, no. 1-3, pp. 572-575, 1995.

[62] M. E. Motamedi, S. Park, A. Wang et al., "Development of micro-electro-mechanical optical scanner," Optical Engineering, vol. 36, no. 5, pp. 1346-1353, 1997.

[63] M. Ataka, A. Omodaka, N. Takeshima, and H. Fujita, "Fabrication and operation of polyimide bimorph actuators for a ciliary motion system," Journal of Microelectromechanical Systems, vol. 2, no. 4, pp. 146-150, 1993.

[64] G. Lin, C.-J. Kim, S. Konishi, and H. Fujita, "Design, fabrication, and testing of A C shape actuator," in Proceedings of the 8th International Conference on Solid-State Sensors and Actuators (Transducers '95 and Eurosensors), Stockholm, Sweden, June 1995.

[65] S. Schweizer, S. Calmes, M. Laudon, and PH. Renaud, "Thermally actuated optical microscanner with large angle and low consumption," Sensors and Actuators A, vol. 76, no. 1-3, pp. 470-477, 1999.

[66] Q. Liu and Q. A. Huang, "Micro-electro-mechanical digitalto-analog converter based on a novel bimorph thermal actuator," in Proceedings of the 1st IEEE International Conference on Sensors, pp. 1036-1041, Orlando, Fla, USA, June 2002.

[67] M. Sinclair, "A high frequency resonant scanner using thermal actuator," in Proceedings of the 15th IEEE International Conference on Micro Electro Mechanical Systems (MEMS '02), Las Vegas, Nev, USA, January 2002.

[68] A. Jain, A. Kopa, Y. Pan, G. K. Feeder, and H. Xie, "A two-axis electrothermal micromirror for endoscopic optical coherence tomography," IEEE Journal on Selected Topics in Quantum Electronics, vol. 10, no. 3, pp. 636-642, 2004.

[69] H. Xie, Y. Pan, and G. K. Fedder, "Endoscopic optical coherence tomographic imaging with a CMOS-MEMS micromirror," Sensors and Actuators A, vol. 103, no. 1-2, pp. 237-241, 2003.

[70] T. Xie, H. Xie, G. K. Fedder, and Y. Pan, "Endoscopic optical coherence tomography with new MEMS mirror," Electronics Letters, vol. 39, no. 21, pp. 1535-1536, 2003.

[71] Y. Xu, J. Singh, C. S. Premachandran et al., "Design and development of a 3D scanning MEMS OCT probe using a novel SiOB package assembly," Journal of Micromechanics and Microengineering, vol. 18, no. 12, Article ID 125005, 2008.

[72] J. Singh, J. H. S. Teo, Y. Xu et al., "A two axes scanning SOI MEMS micromirror for endoscopic bioimaging," Journal of Micromechanics and Microengineering, vol. 18, no. 2, Article ID 025001, 2008.

[73] X. J. Mu, G. Y. Zhou, H. H. Feng et al., "A 3mm endoscopic probe with integrated MEMS micromirror for optical coherence tomography bioimaging, Procedia Engineering," in Proceedings of the 24th Eurosensor Conference, vol. 5, pp. 681684, 2010.

[74] M. Wang, Y. Xu, C. S. Prem et al., "Microfabricated endoscopic probe integrated MEMS micromirror for optical coherence tomography bioimaging," in Proceedings of the IEEE Annual International Conference on Engineering in Medicine and Biology Society (EMBC '10), pp. 57-60, August-September 2010.

[75] J. Sun, S. Guo, L. Wu et al., "3D in vivo optical coherence tomography based on a low-voltage, large-scan-range $2 \mathrm{D}$
MEMS mirror," Optics Express, vol. 18, no. 12, pp. 1206512075,2010

[76] H. Xie, J. Sun, and L. Wu, "Optical micro-endoscopes for 3D in-vivo imaging," in Proceedings of the Electrothermal Micromirrors and a Flexible Printed Circuit Board Permit Fast, Small Optical Coherence Tomography of Internal Organs, SPIE Newsroom, February 2010.

[77] L. Liu, L. Wu, J. Sun, E. Lin, and H. Xie, "Miniature endoscopic optical coherence tomography probe employing a two-axis microelectromechanical scanning mirror with through-silicon vias," Journal of Biomedical Optics, vol. 16, no. 2, 2011. 

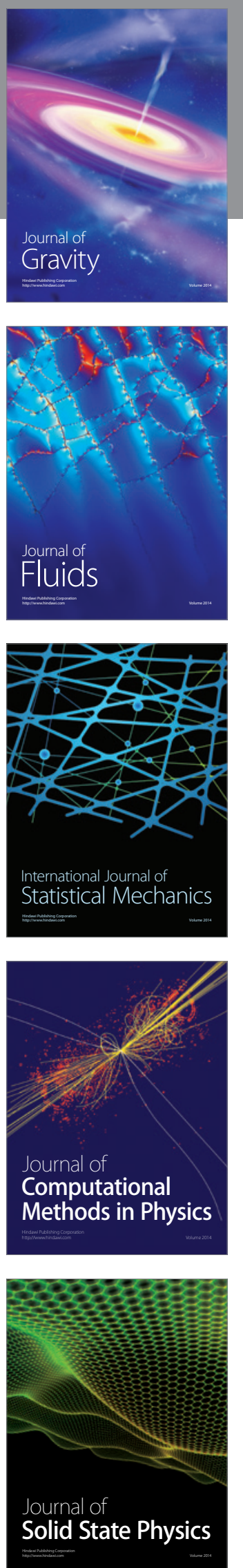

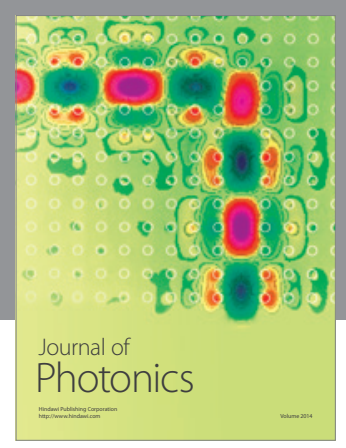

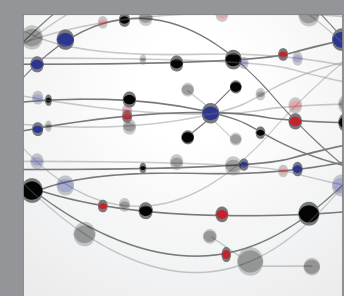

The Scientific World Journal
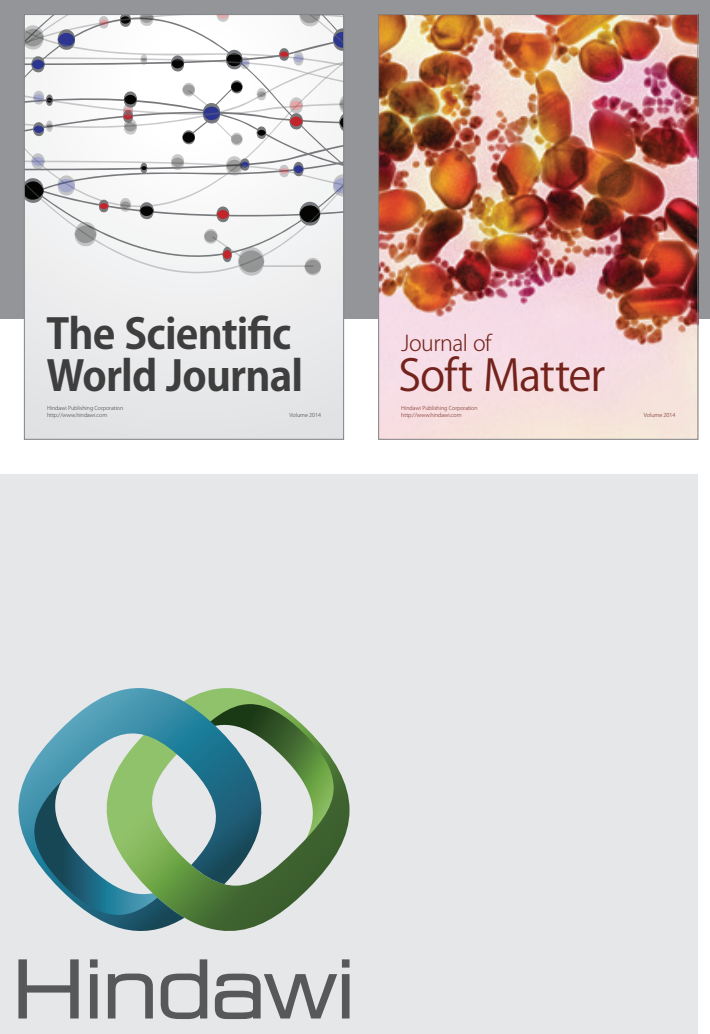

Submit your manuscripts at

http://www.hindawi.com
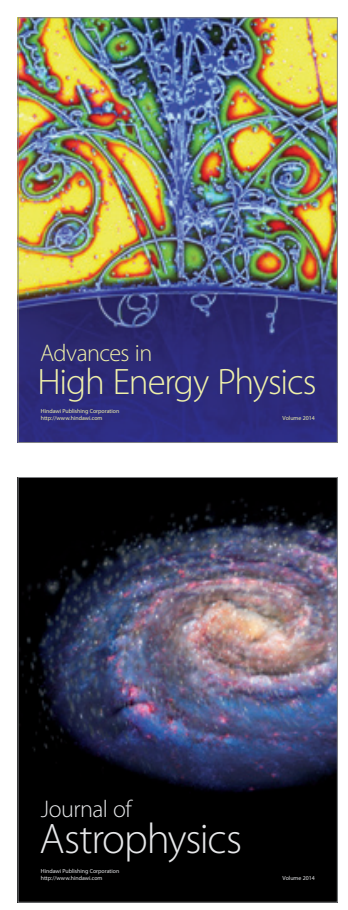
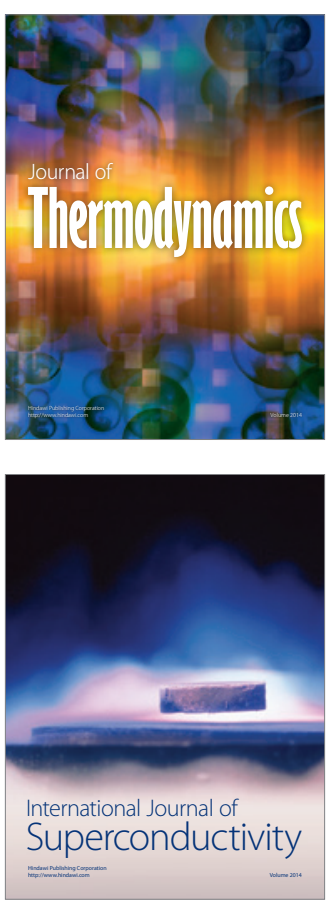
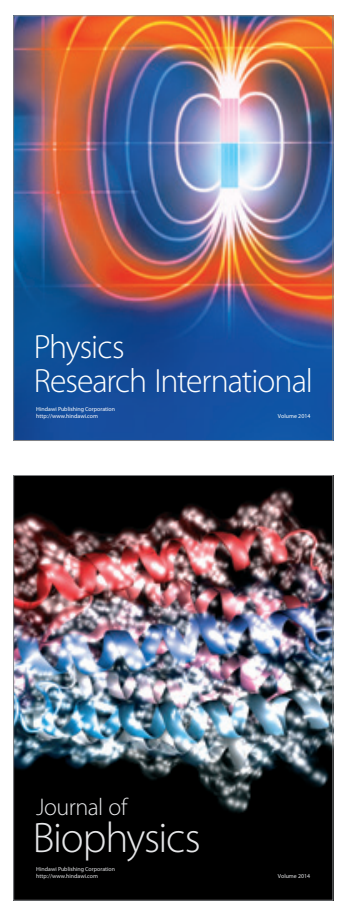
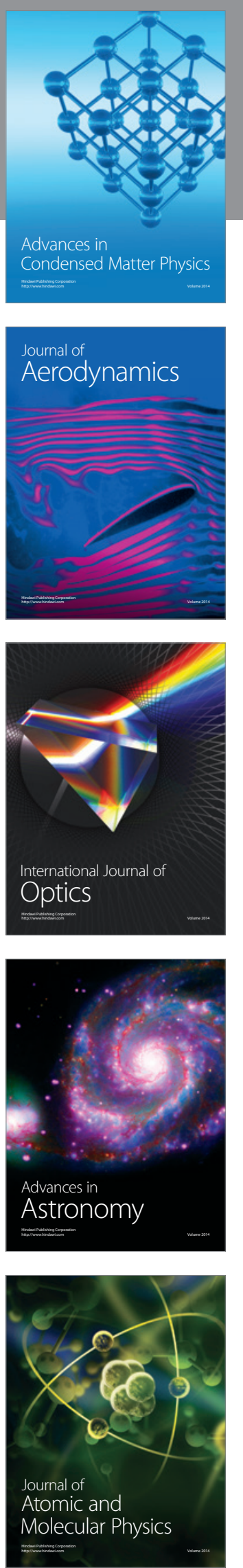